\section{Visual discrimination learning as a function of mode of auxiliary activity and instructed information*}

\author{
JOSEPH C. McLACHLAN \\ Naval Personnel and Training Research Laboratory, San Diego, Calif. 92152 \\ and \\ STEPHEN L. CARMEAN \\ Western Washington State College, Bellingham, Wash. 98225
}

An attempt was made to neutralize the effects of mixed-pattern auxiliary activity (positive stimuli involved on half the trials, negative on the other half) during discrimination learning by giving instructions to rehearse subvocally the names of the positive stimuli and to recall these names. Performance was facilitated by these instructions for groups hearing the names of, or pointing to, the stimuli and depressed for groups saying or writing the names. It was concluded that poor performance with a mixed pattern of auxiliary activity was not due simply to confusion on S's part as to the nature of the task and that $S$ is less able to avoid storing names which are generated by his own activity than those which are imposed upon him.

In previous studies of the effect of auxiliary activity on discrimination learning, it has almost invariably been found that a mixed pattern of activity results in a lower performance level than is found in a comparable control condition (Carmean, 1969; Carmean \& McLachlan, 1967; Carmean \& Weir, 1967; O'Brien \& Carmean, 1967). In these studies, $S$ was required to say, write, or hear the name of one of the pair of stimuli presented on each trial, with the name being that of a correct stimulus on half of the trials and an incorrect stimulus on the other half.

The explanation for the lower performance suggested by Carmean \& Weir (1967) was that the auxiliary activity affected the discrimination performance through an effect on retention, that $S$ tended to remember from trial to trial the names involved in auxiliary activity but to remember less well which names were of correct stimuli. In essence, this is saying that the mixed pattern caused $S$ to store names of both positive and negative stimuli without clearly distinguishing between them and that this undifferentiated storage was a handicap on later trials.

The only group with a mixed pattern which did not perform more poorly than the comparable control group was one in the Carmean \&

*The opinions and assertions contained herein are those of the authors and are not to be construed as official or as reflecting the views of the Navy Department or Naval Service. The authors thank Pacific Northwest Bell for donating the necessary programming equipment and Gernald $M$. Eads II for collecting the data for the control condition. This article is based on a thesis submitted by the first author to Western Washington State College in partial fulfillment of the requirements for the MA degree.
McLachlan (1967) study which heard the names and were instructed to ignore what they were hearing. Explaining that exception was the impetus for this study.

Two possibilities were seriously considered. The first was that these Ss had indeed succeeded in ignoring (and consequently not storing) the mixed pattern of names and thus escaped the subsequent handicap. A complication was introduced by the fact that in the same study, the performance of a group saying the mixed pattern and also instructed to ignore it was even poorer than that of another group saying the same mixed pattern but not given the special instructions. As concluded at the time, this would seem to mean that "one can ignore what he hears but not what he says." Or perhaps, more generally, that one cannot ignore a name which he himself generates, although he can ignore one which is externally generated.

The second alternative was simpler. The mixed pattern of the auxiliary activity confused $\mathrm{S}$ because he tried to find a relationship between the correct discriminatory responses and the auxiliary activity. If this were true, instructions to ignore the auxiliary activity might result in better performance by making clear the irrelevance of that activity. If such instruction could nullify the effects of auxiliary activity, a reexamination of the entire series of experiments would be necessary, since the general explanation offered by Carmean and Weir would clearly be inappropriate. The major piece of evidence against this alternative was the poor performance of the group described above which was instructed to ignore names which they were saying. However, it was possible that this had not been a fair test, since the instructions to ignore the auxiliary activity were not particularly stressed and $\mathbf{S}$ was not questioned to ascertain that he understood them.

\section{METHOD}

The original experiment consisted of eight groups $(\mathrm{N}=16)$ with four modes of auxiliary activity (saying, writing, pointing to, or hearing) and two levels of instructions (standard and special). The pattern of auxiliary activity was mixed-the names of a positive stimulus on half of the trials and a negative stimulus on the other half.

After having examined the results, two control groups $(\mathbf{N}=23)$ without auxiliary activity (one with each level of instructions) were added in order to provide additional comparisons. In all, data were collected for $174 \mathrm{Ss}$.

The apparatus was the same as that described by Carmean \& McLachlan (1967). Ten pairs of animal pictures were rear-projected onto an eye-level screen. The $\mathbf{S}$ indicated his choice by pushing one of two buttons directly below the screen. Choosing the positive stimulus sounded a single-tone door chime. One second following the discriminatory response, one of two blue lights came on, indicating the stimulus for the auxiliary activity if $S$ was in a say, write, or point condition. If he was in a hear condition, a tape recorder played the name of the stimulus. The apparatus cycled 4 sec after the discriminative response.

Two filmstrips with two orders of presentation were used. One animal of each pair was correct for half the Ss, and the other was correct for the other half. Four random patterns were constructed such that all stimulus names were used an equal number of times.

All Ss were given five pretraining trials with a pair of stimuli which did

Table 1

Mean Number of Correct Responses for Each Condition at Each Instructional Level

\begin{tabular}{lccccr}
\hline & \multicolumn{2}{c}{ Standard } & Instructions & & \multicolumn{2}{c}{ Special } & Instructions \\
\cline { 2 - 3 } Condition & Mean & SD & & Mean & SD \\
\hline Hear & 93.2 & 19.0 & 108.4 & 9.2 \\
Point & 91.8 & 17.1 & 101.2 & 9.0 \\
Say & 91.0 & 21.5 & 87.2 & 17.8 \\
Write & 95.3 & 17.0 & 84.1 & 19.8 \\
Control & 107.8 & 5.1 & 108.9 & 9.5 \\
\hline
\end{tabular}


Table 2

Mean Number of Positive and Negative Stimuli Recalled in Each Condition at Each Instructional Level

\begin{tabular}{|c|c|c|c|c|c|c|c|c|}
\hline \multirow{3}{*}{$\begin{array}{c}\text { Condi- } \\
\text { tion }\end{array}$} & \multicolumn{4}{|c|}{ Standard Instructions } & \multicolumn{4}{|c|}{ Special Instructions } \\
\hline & \multicolumn{2}{|c|}{ Positive } & \multicolumn{2}{|c|}{ Negative } & \multicolumn{2}{|c|}{ Positive } & \multicolumn{2}{|c|}{ Negative } \\
\hline & Mean & SD & Mean & SD & Mean & SD & Mean & SD \\
\hline Hear & 7.3 & 2.0 & 5.9 & 1.8 & 7.6 & 1.1 & 6.4 & 1.6 \\
\hline Point & 6.8 & 1.6 & 5.4 & 1.9 & 6.8 & 1.7 & 5.0 & 1.6 \\
\hline Say & 7.2 & 1.5 & 7.1 & 1.1 & 6.9 & 1.5 & 5.9 & 1.3 \\
\hline Write & 7.9 & 1.1 & 6.4 & 1.5 & 6.6 & 1.9 & 6.6 & 2.0 \\
\hline Control & 7.8 & 1.4 & 6.1 & 1.9 & 7.7 & 1.2 & 5.4 & 2.1 \\
\hline
\end{tabular}

not appear in the task proper. At the beginning of pretraining, they were given instructions which indicated to them: (1) that a bell would ring when they chose the correct animal and that the bell would not ring when the incorrect animal was chosen; (2) that they would have to guess which animals were correct the first time through the task but that the pairs would be repeated several times; (3) that the blue light which came on after each choice indicated to them which animal they should say, write, or point to or that the tape recorder would be playing the name of one or another of the animals from each pair.

Following pretraining, the Ss in the special instructions condition were also given these additional instructions: (1) that we were trying to find out what effect irrelevant information had on their being able to learn the correct animals; (2) that what they were saying, writing, pointing to, or hearing was sometimes inconsistent with the correct animal in each pair; (3) that they should try to ignore this information; and (4) that the best way to do this was to say the name of the correct animal to themselves and remember that name when they saw the same pair again.

Noncorrective procedure was followed throughout the experiment. All Ss were told when they had seen all of the 10 pairs for the first time. The experiment was terminated when Ss completed two successive errorless 10-trial blocks or a maximum of 120 trials. For the purpose of analysis, Ss reaching the learning criterion were assumed to have perfect scores for the remainder of the 120 trials. Immediately following completion of the task, $\mathrm{S}$ was given $3 \mathrm{~min}$ to write down the names of all the animals that he could remember. No indication was previously given that this would be required.

\section{RESULTS}

The mean number of correct responses and standard deviations for each of the auxiliary activity conditions and for standard and special instructions are presented in Table 1.

The data from the two control groups were analyzed separately. Neither the effect of instructions $(F<1)$ nor the interaction of Instructions by Trials $(F<1)$ approached significance at the .10 level. The effect of trials $(F=133.94$, $\mathrm{df}=11 / 484, \quad \mathrm{p}<.001) \quad$ was highly significant, reflecting the learning which occurred during the task.

Differences among the experimental groups were evaluated with a nested analysis of variance (Winer, 1962, p. 186) which pooled the groups which generated stimulus name (the say and the write) and those which did not (the hear and the point). Both the difference between groups which generated the names of the stimuli themselves and those which did not $(F=9.51, d f=1 / 120, p<.005)$ and the interaction of Generation of Names by Instructions ( $F=11.90$, $\mathrm{df}=1 / 120, \quad \mathrm{p}<.001$ ) were highly significant. Neither the effect of instructions $(F<1)$, the variance of groups within the same classification with regard to whether or not $S$ generated names (variance between say-and-write groups plus that between hear-and-point groups) $(\mathrm{F}<1)$, nor the interaction of this with instructions $(F<1)$ approached significance.

A Newman-Keuls test for multiple comparisons was used to evaluate pairwise differences. With standard instructions, only the difference between write and say groups was significant beyond the .01 level. With special instructions, all comparisons were significant beyond the .01 level except those between write and say groups which did not reach the .05 level. Comparing special instructions groups with the corresponding standard instructions groups, all differences were significant beyond the .01 level except those between say groups which were beyond the .05 level.

The mean number of positive and negative stimuli recalled and associated standard deviations for each of the auxiliary activity conditions and each level of instructions are presented in Table 2.

The recall data for control and experimental groups were also analyzed separately. As in previous studies, significantly more positive than negative stimuli were recalled $(F=27.56, \mathrm{df}=1 / 30, \mathrm{p}<.001)$ in the control condition. Neither the instructions effect $(F=1.40$, $\mathrm{df}=1 / 44$ ) nor the Stimulus Valence by Instruction interaction $(F<1)$ reached the .10 level of significance.

The difference in total recall (positive plus negative) associated with condition was significant at the .05 level $(F=3.45$, $d f=3 / 120)$. This was largely due to the consistently lower recall by groups in the point condition. As in the control conditions, significantly more positive than negative stimuli were recalled $(F=37.08, \quad$ df $=1 / 120, \quad p<.001)$. None of the other effects reached the .10 level: instructions, $F=1.42$, df $=1 / 120 ;$ Conditions by Instructions, $\mathrm{F}=1.27, \mathrm{df}=3 / 120$; Valence by Conditions, $F=1.96$, df $=3 / 120$; Valence by Instructions, $\mathbf{F}<1$; and Valence by Conditions by Instructions, $F=2.12$, df $=3 / 120$.

$$
\text { DISCUSSION }
$$

From the results, it was concluded that the second hypothesis discussed in the introduction could be ruled out. That is, poorer performance with a mixed pattern of auxiliary activity was not due simply to confusion as to the nature of the task. The other alternative discussed was that perhaps $S$ could avoid storing names if they were imposed upon him but that he could not do so if he were generating them himself. The significant main effect of generation of names supports this position. In fact, the write/special-instructions and the say/special-instructions groups made significantly fewer correct responses than did the groups with the same types of auxiliary activity but given only standard instructions. There is no explanation of why the special instructions should increase errors for these conditions, although it is evident that the strategy suggested by the special instructions would be a poor one if $S$ could not avoid storing the names involved in the auxiliary activity and could not clearly distinguish this storage from that resulting from subvocal rehearsal of the correct stimuli. It may be that with normal instructions, some Ss are less handicapped by the auxiliary activity because they avoid relying upon verbal storage, perhaps by using mnemonic aids such as concepts or imagery.

The hear/special-instructions group learned as quickly as the control group with special instructions, which seems to indicate that in this condition, the instructions completely nullified the usual inhibitory effect of the mixed auxiliary activity pattern. However, 
the control/special-instructions group did not perform significantly better than the control/normal-instructions group, and it may not, therefore, be a representative standard to use in reaching such a conclusion.

The recall of the hear/specialinstructions group was also of interest. With mixed-pattern auxiliary activity in previous studies, recall included approximately equal numbers of positive and negative stimuli. With a positive pattern and to a lesser extent in the control condition, more positive than negative stimuli were recalled. Extrapolating from this, the prediction was that if the special instructions were followed and the auxiliary activity ignored, positive stimuli would predominate in the recall, and that, in essence, these instructions would remove $S$ from a mixed pattern condition and place him in the equivalent of a positive-pattern condition. This prediction was substantially supported as the performance of the hear/specialinstructions group was as good as the performance of the control, and significantly more $(t=2.43, d f=30$, $\mathrm{p}<.05)$ positive than negative stimuli were recalled.

\section{REFERENCES}

CARMEAN, S. L. Effects of pattern of auxiliary activity on discrimination learning of children. Child Development $1969,40,928-934$

CARMEAN, S. L., \& MCLACHLAN, J. C. $V$ isual discrimination learning: Interactions of auditory input pattern. verbalization, and instructions. Psychonomic Science, 1967, 8, 311-312.

CARMEAN, S. L., \& WEIR. M. W. Effects of verbalizations on discrimination learning and retention. Journal of Verbal Learning \& Verbal Behavior, 1967, 6, 545-550.

O'BRIEN, G. L., \& CARMEAN, S. L. Verbalizing and writing as auxiliary responses during discrimination learning. Psychonomic Science, 1967, 9, 335-336.

WINER, B. J. Statistical principles in experimental design. New York: McGraw-Hill, 1962. 